\title{
Role of Intestinal Flora on the Metabolism, Absorption, and Biological Activity of Dietary Flavonoids
}

\author{
Motoi Tamura, ${ }^{1 *}$ Kazuhiro Hirayama ${ }^{2}$ and Kikuji Itoh ${ }^{2}$ \\ ${ }^{1}$ National Food Research Institute, Tsukuba 305-8642, Japan \\ ${ }^{2}$ Laboratory of Veterinary Public Health, Graduate School of Agricultural and Life Sciences, The University of Tokyo, Tokyo 113-8657, \\ Japan \\ Received for publication, June 10, 2003
}

\begin{abstract}
Much attention has been focused on flavonoids because of their beneficial effects on human health. Flavonoids are the most abundant dietary polyphenols. Quercetin is one of the major flavonoids and is contained in many foods. Soybean and soy foods are rich sources of isoflavones. Recent research has shown that they are beneficial to human health. The two major sites of flavonoid metabolism are the liver and the intestinal flora. Intestinal flora play an important role in the absorption and metabolism of flavonoids. Many of the flavonols including quercetin occur in food in the form of $O$ glycosides, with D-glucose as the most common sugar residue. With respect to the bioavailability of flavonoid glycosides, intestinal flora are known to have an important role in hydrolysis. Colonic flora are known to catalyze the breakdown of flavonoids. It was also found that suppressing the breakdown of quercetin by intestinal flora is important for achieving higher concentrations of quercetin in the plasma. Soy isoflavone aglycone is absorbed faster and in higher amounts than glucosides in humans. Some dietary components are also known to affect the absorption of isoflavones. Human metabolism and excretion of isoflavones following the consumption of soy products show considerable variation. The bioavailability of soybean isoflavones to women is dependant on gut microflora. Equol is a metabolite of daidzein produced by intestinal flora. Equol has many biological activities relates to human health, and its production might be affected by dietary composition and intestinal floral composition. To achieve higher production of equol from daidzein in the gut, control of the metabolic activity of intestinal flora might be of importance.
\end{abstract}

Key words: flavonoid; quercetin; rutin; daidzein; genistein; equol; intestinal flora; metabolism; absorption

\section{INTRODUCTION}

Epidemiological studies suggest a relationship between the daily consumption of fruits and vegetables and prevention of various pathologies such as cancer and cardiovascular disease. Fruits and vegetables are the major dietary source of flavonoids $(35,38,65)$. These compounds comprise one of the largest groups of secondary plant metabolites and are known to occur widely throughout the plant kingdom. In recent years, much attention has been focused on flavonoids because of their beneficial effects on human health. Flavonoids are the most abundant dietary polyphenols. The structures of some flavonoid families (flavone, isoflavone, flavonol, flavanone, flavanonol, flavanol, anthocyanidin) are shown in Fig. 1. These compounds are potent radical scavengers and metal chelators due to their polyphenolic structure. The electron-donating properties of flavonoids have been shown to be the basis of their antioxidant action $(30,50,63)$. Quercetin is one

*Corresponding author. Mailing address: National Food Research Institute, 2-1-12, Kannondai, Tsukuba 305-8642, Japan. Phone: +81-298-388089. Fax: +81-298-38-7996. E-mail: motoita@nfri.affrc.go.jp of the major flavonoids and is contained in many foods. Soybean and soy foods are rich sources of isoflavones. Recent research has shown that they are beneficial to health. Many of the beneficial properties of guercetin $(17,27,45,52,64,73)$ and isoflavones $(3,4,8,9,44$, 48 ) have been reported. In this review, we describe some of the main members of the flavonoid genre, namely, quercetin, rutin and isoflavones. The two major sites of flavonoid metabolism are the liver and the intestinal flora. The intestinal wall and kidney may play a role. Absorbed flavonoids and their related colonic metabolites are glucuronidated and sulfated by the liver in humans and rodents $(15,25,46,71)$. Unabsorbed flavonoids and flavonoid conjugates are secreted with bile into the gut and are degraded by intestinal flora in the lower intestine. The hydrolysis of conjugates and glycosides and ring fission of the aglycones to phenolic acid are the main actions of intestinal flora $(20,21)$. Thus, intestinal flora play an important role in the absorption and metabolism of flavonoids.

\section{ABSORPTION OF QUERCETIN AND QUERCETIN-3-RUTINOSIDE (RUTIN)}

Quercetin, the main flavonol in our diet, is present in 
<smiles>O=c1cc(-c2ccc(O)c(O)c2)oc2cc(O)cc(O)c12</smiles>

Luteolin (flavone)<smiles>O=c1c(-c2ccc(O)cc2)coc2cc(O)cc(O)c12</smiles>

Genistein (isoflavone)<smiles>O=C1c2c(O)cc(O)cc2OC(c2ccc(O)c(O)c2)C1O</smiles>

Taxifolin (flavanonol)<smiles></smiles>

Cyanidin (anthocyanidin)

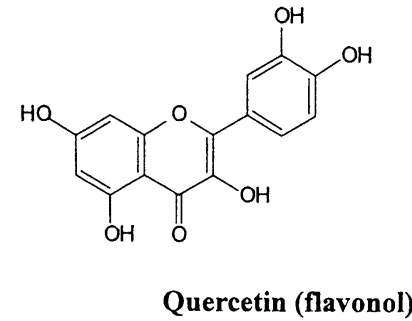<smiles>COc1ccc(C2CC(=O)c3c(O)cc(O)cc3O2)cc1O</smiles>

Hesperetin (flavanone)<smiles>Oc1cc(O)c2c(c1)OC(c1ccc(O)c(O)c1)C(O)C2</smiles>

Catechin (flavanol)

Fig. 1. Structures of some flavonoid families.

many fruits, vegetables, and beverages. It is particularly abundant in onions (22) and tea (23). There are some reports on the metabolism and absorption of quercetin and rutin after feeding with supplemented diets (37). Manach et al. reported the bioavailability of rutin and quercetin in rats. Conjugated derivatives of quercetin and its methylated forms (isorhamnetin and tamarixetin) were recovered in plasma, although after 10 days, no tamarixetin was detected. Rutin was shown to be absorbed more slowly than quercetin. Manach et al. suggested that rutin might not be absorbed from the small intestine because of its sugar moiety. It is now known that rutin must be hydrolyzed by cecal microflora. Evidence suggests that quercetin is absorbed faster than rutin. However, in healthy ileostomy volunteers, quercetin glucosides from onions were more readily absorbed than the aglycone form (25). The bioavailability of pure rutin was $30 \%$ relative to the quercetin from onions, which contain only quercetin-glucosides (26). These reports indicate the important role of sugar moiety in the bioavailability and absorption of dietary quercetin in the human body. Many of the flavonols including quercetin occur in food in the form of $O$-glycosides, with D-glucose as the most common sugar residue. Other 
sugar residues are D-galactose, L-rhamnose, L-arabinose, D-xylose, and D-glucuronic acid (24). Glycosylation influences the chemical, physiological and biological properties of flavonoids.

\section{THE EFFECTS OF INTESTINAL FLORA ON THE METABOLISM OF QUERCETIN AND RUTIN}

The chemical structures of flavonoids influence their rate and extent of intestinal absorption and also the types of flavonoid metabolites circulating in the plasma. Rutin is a rhamnoglucoside of quercetin that requires deglycosylation by the intestinal flora prior to absorption in the colon (26). Flavonoids including quercetin are usually glycosylated. It has been reported that the rate of deglycosylation of quercetin 3-glucoside with cell-free extracts of small intestine was low and that rutin was not hydrolyzed (16). However, rutin was shown to be hydrolyzed by the colonic flora. With respect to the bioavailability of flavonoid glycosides, intestinal flora are known to have an important role in hydrolysis. Rutin and quercetin-3-O-rhamnoside are not hydrolyzed by endogenous human enzymes. But they are hydrolyzed by intestinal flora to quercetin. Intestinal bacteria such as Bacteroides distasonis ( $\alpha$ rhamnosidase and $\beta$-glucosidase), $B$. uniformis ( $\beta$-glucosidase), and Bacteroides ovatus ( $\beta$-glucosidase) were able to catalyze this reaction (12). Enterococcus casseliflavus is able to hydrolyze quercetin-3-O-glucoside but does not metabolize aglycone. Quercetin-3-Oglucoside is known to be transformed to 3,4-dihydroxyphenylacetic acid, acetate, and butyrate by Eubacterium ramulus (54). Tamura et al. studied the effects of intestinal flora on plasma quercetin concentrations (69). Tamura et al. demonstrated that intestinal flora decompose much of the dietary quercetin in the cecum. It was also found that suppressing the breakdown of quercetin by intestinal flora is important for achieving higher concentrations of quercetin in the plasma. Colonic flora are known to catalyze the breakdown of flavonoids. Following the incubation of quercetin-3-O-rhamnoside with intestinal bacteria, quercetin, 3,4-dihydroxyphenylacetic acid and 4-hydroxybenzoic acid were found to be the metabolites. When rutin and quercetin are administered to humans, the metabolites produced by the breakdown caused by colonic flora are 3-hydroxyphenylacetic acid, 3-methoxy-4-hydroxyphenylacetic acid, 3,4-dihydroxyphenylacetic acid, 3,4dihydroxytoluene, and $\beta$ - $m$-hydroxyphenylhydracrylic acid. These compounds have been detected in human urine, while the parent compound, rutin, was not (10).

\section{ABSORPTION OF DAIDZEIN, GENISTEIN, DAIZIN, AND GENISTIN}

The main dietary source of isoflavone is soybean and soy foods $(13,43)$. The main components of isoflavones are daidzin, genistin, daizein (aglycone of daidzin), and genistein (aglycone of genistin). Isoflavones belong to the group of phytoestrogens. Phytoestrogens are estrogenic compounds found in plants. The phytoestrogens are defined as compounds that exert estrogenic effects on the central nervous system, induce estrus, and stimulate the growth of the genital tract of female animals (36). King and Bursill showed that genistein and daidzein are absorbed by humans (32). Human metabolism and excretion of isoflavones following the consumption of soy products show considerable variation $(28,31,75)$. It has been shown that Japanese men and women have significantly higher concentrations of daidzein, genistein, and equol than individuals from the UK (41). The bioavailability of soybean isoflavones to women is dependant on gut microflora (75). The average plasma concentration of genistein at $24 \mathrm{hr}$ after a breakfast-based isoflavone dose in subjects excreting large amounts of fecal isoflavones was significantly greater than in subjects who excreted small amounts of fecal isoflavones $(2.5$-fold, $p<0.05)$. Soy food processing also influences isoflavone bioavailability. Urinary isoflavone excretion was found to be similar in 17 male subjects who consumed either $112 \mathrm{~g}$ of fermented soy tempeh or $125 \mathrm{~g}$ of unfermented soybean for nine days (28). However, urinary recovery of daidzein and genistein was higher in subjects that consumed the tempeh diet. The data suggest that the isoflavone aglycones in fermented food may be more bioavailable than their glucosides. Soy isoflavone aglycone is absorbed faster and in higher amounts than glucosides in humans (29). Setchell et al. demonstrated that isoflavone glycosides were not intact when absorbed across the enterocyte of healthy adults, and their bioavailability required initial hydrolysis of the sugar moiety by intestinal $\beta$-glucosidases prior to uptake (58). In contrast, Richelle et al. investigated the hydrolysis of isoflavone glycosides to aglycone by $\beta$-glucosidase (51). It was found that hydrolysis does not alter the plasma and urinary isoflavone pharmacokinetics in postmenopausal women. Richelle et al. explained that the difference could be due to the food matrix in which the isoflavones were incorporated and whether they were given as pure isoflavones, as soy protein isolates, or as enriched isoflavone extracts (51). Other dietary components are also known to affect the absorption of isoflavones. 
Fiber-rich diets have been shown to lead to a 55\% lower plasma genistein concentration and to reduced urinary genistein by $20 \%, 24 \mathrm{hr}$ after soy dosing $(p<0.05)$ (70). Dietary isoflavones undergo enterohepatic circulation (74). When $4-{ }^{14} \mathrm{C}$-genistein is infused into the duodenum of rats, it is rapidly absorbed from the intestine, taken up by the liver, and excreted into the bile as its $7-O-\beta$-glucuronide conjugate (61). Intestinal perfusion studies have indicated that some of the genistein glucuronide produced in the rat small intestine is returned to the lumen (5-7). Intestinal flora appear to be the major source of $\beta$-glucuronidase in the gut (34). Higher floral $\beta$-glucuronidase activity may lead to efficient re-absorption of the genistein by hydrolyzing the bile excretory genistein-glucuronide and genisteinglucuronide formed in the small intestine and returned to the lumen.

\section{EFFECTS OF INTESTINAL FLORA ON METABOLISM OF DAIDZEIN AND GENISTEIN}

Intestinal flora play a key role in the metabolism and bioavailability of isoflavones (57). Both equol and $o-$ desmethylangolensin are metabolic products of daidzein produced by intestinal flora $(1,11) . \rho$-Ethylphenol is a metabolite of genistein produced by intestinal flora (20). Equol is considerably more estrogenic than daidzein or o-desmethylangolensin (62), another major bacterial metabolite of daidzein. $\rho$-Ethylphenol is an inactive metabolite. Intestinal flora seem to have an important influence on the effects of isoflavones on the host. Studies have shown that only about $30-40 \%$ of the subjects excreted significant quantities of equol after isoflavone consumption $(33,57)$. Infants fed infant formula containing soy in the first 4 months of life (when gut microflora are underdeveloped) cannot form large quantities of equol $(14,60)$. It was demonstrated that the floral composition of the soy protein diet group was significantly different from that of the casein diet group (67). In an experiment investigating the in vitro incubation of daidzein with the fecal flora of mice, it was found that equol concentrations were significantly higher in mice fed a soy protein diet as compared with the casein diet group (68). Tamura et al. demonstrated that, in mice, plasma equol concentrations were significantly higher in the soy protein-isoflavone diet group than in the casein-isoflavone diet group (68). In this experiment, the composition of intestinal flora differed between the two dietary groups. Lactobacilli was much more abundant in the soy protein-isoflavone diet group than in the casein-isoflavone diet group. Fusiform-shaped bacteria were significantly fewer in the soy protein-isoflavone diet group than in the caseinisoflavone diet group. Clearly, changes in the floral composition affected by different protein sources may increase the rate of conversion of daidzein to equol. The composition of intestinal flora might have an important influence on the production of equol from daidzein in the gut. Using an in vitro model of the human colonic fermentation system, it was shown that the conversion of daidzein to equol by cultured human fecal flora could be achieved. In the presence of large quantities of carbohydrates, the rate of the conversion of daidzein to equol is increased $(55,59)$. Rowland et al. demonstrated that good equol producers consumed less fat as a percentage of energy than poor excretors and more carbohydrate as a percentage of energy than poor excretors (53). Rowland et al. also suggested that dietary fat intake decreases the capacity of intestinal flora to synthesize equol (53). These reports suggest that dietary composition plays an important role in the conversion of daidzein to equol. Tamura et al. also demonstrated that plasma equol concentrations were significantly higher in a potato starch-isoflavone diet group than in the rice starch-isoflavone diet group (66). The number of bifidobacteria in the potato starchisoflavone diet group was significantly higher than that of the rice-isoflavone diet group. These results suggest that not only a higher percentage of carbohydrate in the diet, but also the type of carbohydrate might influence the rate of conversion of daidzein to equol. The relationship between the higher number of bifidobacteria and the higher plasma equol concentrations in the potato starch-isoflavone diet group should be studied in greater detail. Prebiotics also affect equol production. Ohta et al. showed that dietary fructooligosaccharides increase equol production from daidzein in ovariectomized mice (47). Probiotics also affect the composition of intestinal flora (19). The use of probiotics might also affect equol production from daidzein.

\section{BIOLOGICAL ACTIVITY OF EQUOL}

Shutt and Cox (62) reported that equol displays higher estrogenic activity than daidzein. The binding affinity of equol for human ER $\alpha$ and ER $\beta$ was found to be similar to that of genistein. Daidzein was shown to have poor affinity in these experiments (40). Equol is a more effective antioxidant than daidzein or genistein $(39,72)$. The higher antioxidant activity of equol would lead to greater inhibition of lipid peroxidation and contribute to a reduction in the risk of cardiovascular disease. It has been demonstrated that soybean protein and 
isoflavone supplementation prevents postmenopausal bone loss in humans (49). Ohta et al. (47) demonstrated that increased concentrations of equol in the plasma of mice fed a diet containing fructooligosaccharideisoflavone might have a lower incidence of distal and trabecular bone loss. Several studies support the hypothesis that adequate dietary isoflavone intake reduces the risk of cancer $(2,56)$. Prostatic cancer is known to be responsive to estrogen therapy. Asian men, who are considered to be at a lower risk of prostate cancer relative to European men, were found to have higher concentrations of isoflavones, equol, and daidzein in plasma and prostatic fluids (42). Duncan et al. demonstrated that the relationship between equol excretion and lowered breast cancer risk may reflect the tendency of equol excretors to have more favorable hormonal profiles, as opposed to merely reflecting increased isoflavone intake (18).

\section{CONCLUSION}

Intestinal flora influence the bioavailability of flavonoids. In order to obtain higher plasma quercetin, daidzein, and genistein concentrations, suppressing the breakdown of these flavonoids by intestinal flora is needed. Increasing the activity of $\beta$-glucosidase by intestinal flora to hydrolyze the flavonoid glucoside to aglycone is also advantageous. Equol is a metabolite of daidzein produced by intestinal flora. It has many biological activities related to human health, and its production might be affected by dietary composition and intestinal floral composition. To achieve higher production of equol from daidzein in the gut, control of the metabolic activity of intestinal flora might be of importance. To control floral composition by dietary intake, the use of prebiotics in order to increase the rate of production of equol from daidzein in the gut seems to increase the health effects of isoflavones on the host.

\section{REFERENCES}

(1) Adlercreutz H, Fotsis T, Heikkinen R, Dwyer JT, Woods M, Goldin BR, Gorbach SL. 1982. Excretion of the lignans enterolactone and enterodiol and of equol in omnivorous and vegetarian postmenopausal women and in women with breast cancer. Lancet 2: 1295-1299.

(2) Adlercreutz H, Goldin BR, Gorbach SL, Höckerstedt KAV, Watanabe S, Hämäläinen EK, Markkanen MH, Mäkelä TH, Wähälä KT, Adlercreutz T. 1995. Soybean phytoestrogen intake and cancer risk. J Nutr 125: 757S-770S.

(3) Adlercreutz H, Höckerstedt K, Bannwart C, Bloigu S, Hämäläinen E, Fotsis T, Ollus A. 1987. Effect of dietary components, including lignans and phytoestrogens, on enterohepatic circulation and liver metabolism of estrogens and on sex hormone binding globulin (SHBG). J Steroid Biochem 27: 1135-1144.

(4) Anderson JJ, Ambrose WW, Garner SC. 1995. Orally dosed genistein from soy and prevention of cancellous bone loss in two ovariectomized rat models. J Nutr 125: 799S.

(5) Andlauer W, Kolb J, Fürst P. 2000. Absorption and metabolism of genistein in the isolated rat small intestine. FEBS Lett 475: 127-130.

(6) Andlauer W, Kolb J, Fürst P. 2000. Isoflavones from tofu are absorbed and metabolized in the isolated rat small intestine. J Nutr 130: 3021-3027.

(7) Andlauer W, Kolb J, Stehle P, Fürst P. 2000. Absorption and metabolism of genistein in isolated rat small intestine. J Nutr 130: 843-846.

(8) Anthony MS, Clarkson TB, Hughes CL Jr, Morgan TM, Burke GL. 1996. Soybean isoflavones improve cardiovascular risk factors without affecting the reproductive system of peripubertal rhesus monkeys. J Nutr 126: 43-50.

(9) Arjmandi BH, Alekel L, Hollis BW, Amin D, StacewiczSapuntzakis M, Guo P, Kukreja SC. 1996. Dietary soybean protein prevents bone loss in an ovariectomized rat model of osteoporosis. J Nutr 126: 161-167.

(10) Baba S, Furuta T, Fujioka M, Goromaru T. 1983. Studies on drug metabolism by use of isotopes. XXVII. Urinary metabolites of rutin in rats and role of intestinal microflora in the metabolism of rutin. J Pharm Sci 72: 1155-1158.

(11) Bannwart C, Adlercreutz H, Fotsis T, Wähälä K, Hase T, Brunow G. 1984. Identification of $o$-desmethylangolensin, a metabolite of daidzein and of matairesinol, one likely plant precursor of the animal lignan enterolactone in human urine. Finn Chem Lett 4/5: 120-125.

(12) Bokkenheuser VD, Shackleton CHL, Winter J. 1987. Hydrolysis of dietary flavonoid glycosides by strains of intestinal Bacteroides from humans. Biochem J 248: 953-956.

(13) Coward L, Barnes NC, Setchell KDR, Barnes S. 1993. Genistein, daidzein, and their $\beta$-glycoside conjugates: antitumor isoflavones in soybean foods from American and Asian diets. J Agric Food Chem 41: 1961-1967.

(14) Cruz MLA, Wong WW, Mimouni F, Hachey DL, Setchell KDR, Klein PD, Tsang RC. 1994. Effects of infant nutrition on cholesterol synthesis rates. Pediatr Res 35: 135140.

(15) Das NP, Sothy SP. 1971. Studies on flavonoid metabolism. Biliary and urinary excretion of metabolites of $(+)-\left[\mathrm{U}-{ }^{14} \mathrm{C}\right]$ catechin. Biochem J 125: 417-423.

(16) Day AJ, DuPont MS, Ridley S, Rhodes M, Rhodes MJC, Morgan MRA, Williamson G. 1998. Deglycosylation of flavonoid and isoflavonoid glycosides by human small intestine and liver $\beta$-glucosidase activity. FEBS Lett 436: 71-75.

(17) Deschner EE, Ruperto JF, Wong GY, Newmark HL. 1993. The effect of dietary quercetin and rutin on AOM-induced acute colonic epithelial abnormalities in mice fed a highfat diet. Nutr Cancer 20: 199-204.

(18) Duncan AM, Merz-Demlow BE, Xu X, Phipps WR, Kurzer MS. 2000. Premenopausal equol excretors show plasma hormone profiles associated with lowered risk of breast cancer. Cancer Epidemiol Biomarkers Prev 9: 581-586. 
(19) Fujiwara S. 2002. Bifidobacterium longum SBT2928 and its biological significance. Bioscience Microflora 21: 225238.

(20) Griffiths LA, Smith GE. 1972. Metabolism of apigenin and related compounds in the rat. Metabolite formation in vivo and by the intestinal microflora in vitro. Biochem $\mathrm{J} \mathbf{1 2 8}$ : 901-911.

(21) Griffiths LA, Smith GE. 1972. Metabolism of myricetin and related compounds in the rat. Metabolite formation in vivo and by the intestinal microflora in vitro. Biochem $\mathbf{J}$ 130: $141-151$.

(22) Hertog MGL, Hollman PCH, Katan MB. 1992. Content of potentially anticarcinogenic flavonoids of 28 vegetables and 9 fruits commonly consumed in the Netherlands. J Agric Food Chem 40: 2379-2383.

(23) Hertog MGL, Hollman PCH, van de Putte B. 1993. Content of potentially anticarcinogenic flavonoids in tea infusions, wine and fruit juices. J Agric Food Chem 41: 12421246.

(24) Hertog MGL, Katan MB. 1998. Quercetin in foods, cardiovascular disease, and cancer. In Flavonoids in Health and Disease, Rice-Evans CA, Packer L (eds), Marcel Dekker, New York, p. 447-467.

(25) Hollman PCH, de Vries JHM, van Leeuwen SD, Mengelers MJB, Katan MB. 1995. Absorption of dietary quercetin glycosides and quercetin in healthy ileostomy volunteers. Am J Clin Nutr 62: 1276-1282.

(26) Hollman PCH, van Trijp JMP, Buysman MNCP, Gaag MS, Mengelers MJB, de Vries JHM, Katan MB. 1997. Relative bioavailability of the antioxidant flavonoid quercetin from various foods in man. FEBS Lett 418: 152-156.

(27) Husain SR, Cillard J, Cillard P. 1987. Hydroxy radical scavenging activity of flavonoids. Phytochemistry 26: 24892492.

(28) Hutchins AM, Slavin JL, Lampe JW. 1995. Urinary isoflavonoid phytoestrogen and lignan excretion after consumption of fermented and unfermented soy products. $J$ Am Diet Assoc 95: 545-551.

(29) Izumi T, Piskula MK, Osawa S, Obata A, Tobe K, Saito M, Kataoka S, Kubota Y, Kikuchi M. 2000. Soy isoflavone aglycones are absorbed faster and in higher amounts than their glucosides in humans. J Nutr 130: 1695-1699.

(30) Jovanovic SV, Steenken S, Tosic M, Marjanovic B, Simic MG. 1994. Flavonoids as antioxidants. J Am Chem Soc 116: 4846-4851.

(31) Kelly GE, Joannou GE, Reeder AY, Nelson C, Waring MA. 1995. The variable metabolic response to dietary isoflavones in humans. Proc Soc Exp Biol Med 208: 40-43.

(32) King RA, Bursill DB. 1998. Plasma and urinary kinetics of the isoflavones daidzein and genistein after a single soy meal in humans. Am J Clin Nutr 67: 867-872.

(33) Lampe JW, Karr SC, Hutchins AM, Slavin JL. 1998. Urinary equol excretion with a soy challenge: influence of habitual diet. Proc Soc Exp Biol Med 217: 335-339.

(34) Larsen GL. 1988. Deconjugation of biliary metabolites by microfloral $\beta$-glucuronidases, sulphatases and cysteine conjugate $\beta$-lyases and their subsequent enterohepatic circulation. In Role of the Gut Flora in Toxicity and Cancer,
Rowland IR (ed), Academic Press, London, p. 79-107.

(35) Larson RA. 1988. The antioxidants of higher plants. Phytochemistry 27: 969-978.

(36) Lieberman S. 1996. Are the differences between estradiol and other estrogens, naturally occurring or synthetic, merely semantical? J Clin Endocrinol Metab 81: 850-851.

(37) Manach C, Morand C, Demigné C, Texier O, Régérat F, Rémésy C. 1997. Bioavailability of rutin and quercetin in rats. FEBS Lett 409: 12-16.

(38) Mazza G. 1995. Anthocyanins in grapes and grape products. Crit Rev Food Sci Nutr 35: 341-371.

(39) Mitchell JH, Gardner PT, McPhail DB, Morrice PC, Collins AR, Duthie GG. 1998. Antioxidant efficacy of phytoestrogens in chemical and biological model systems. Arch Biochem Biophys 360: 142-148.

(40) Morito K, Hirose T, Kinjo J, Hirakawa T, Okawa M, Nohara T, Ogawa S, Inoue S, Muramatsu M, Masamune Y. 2001. Interaction of phytoestrogens with estrogen receptors $\alpha$ and $\beta$. Biol Pharm Bull 24: 351-356.

(41) Morton MS, Arisaka O, Miyake N, Morgan LD, Evans BAJ. 2002. Phytoestrogen concentrations in serum from Japanese men and women over forty years of age. J Nutr 132: 3168-3171.

(42) Morton MS, Chan PSF, Cheng C, Blacklock N, MatosFerreira A, Abranches-Monteiro L, Correia R, Lloyd S, Griffiths K. 1997. Lignans and isoflavonoids in plasma and prostatic fluid in men: samples from Portugal, Hong Kong, and the UK. Prostate 32: 122-128.

(43) Murphy PA. 1982. Phytoestrogen content of processed soybean products. Food Technol 36: 62-64.

(44) Naim M, Gestetner B, Bondi A, Birk Y. 1976. Antioxidative and antihemolytic activities of soybean isoflavones. J Agric Food Chem 24: 1174-1177.

(45) Negre-Salvayre A, Salvayre R. 1992. Quercetin prevents the cytotoxicity of oxidized LDL on lymphoid cell lines. Free Radic Biol Med 12: 101-106.

(46) Nielsen SE, Breinholt V, Justesen U, Cornett C, Dragsted LO. 1998. In vitro biotransformation of flavonoids by rat liver microsomes. Xenobiotica 28: 389-401.

(47) Ohta A, Uehara M, Sakai K, Takasaki M, Adlercreutz H, Morohashi T, Ishimi Y. 2002. A combination of dietary fructooligosaccharides and isoflavone conjugates increases femoral bone mineral density and equol production in ovariectomized mice. J Nutr 132: 2048-2054.

(48) Peterson G, Barnes S. 1991. Genistein inhibition of the growth of human breast cancer cells: independance from estrogen receptors and the multi-drug resistance gene. Biochem Biophys Res Commun 179: 661-667.

(49) Potter SM, Baum JA, Teng H, Stillman RJ, Shay NF, Erdman JW Jr. 1998. Soy protein and isoflavones: their effects on blood lipids and bone density in postmenopausal women. Am J Clin Nutr 68: 1375S-1379S.

(50) Rice-Evans CA, Miller NJ, Bolwell PG, Bramley PM, Pridham JB. 1995. The relative antioxidant activities of plant-derived polyphenolic flavonoids. Free Radic Res 22: 375-383.

(51) Richelle M, Pridmore-Merten S, Bodenstab S, Enslen M, Offord EA. 2002. Hydrolysis of isoflavone glycosides to 
aglycones by $\beta$-glycosidase dose not alter plasma and urine isoflavone pharmacokinetics in postmenopausal women. $\mathbf{J}$ Nutr 132: 2587-2592.

(52) Robak J, Gryglewski RJ. 1988. Flavonoids are scavengers of superoxide anions. Biochem Pharmacol 37: 837-841.

(53) Rowland IR, Wiseman H, Sanders TA, Adlercreutz H, Bowey EA. 2000. Interindividual variation in metabolism of soy isoflavones and lignans: influence of habitual diet on equol production by the gut microflora. Nutr Cancer 36: 27-32.

(54) Schneider H, Schwiertz A, Collins MD, Blaut M. 1999. Anaerobic transformation of quercetin-3-glucoside by bacteria from the human intestinal tract. Arch Microbiol 171: 81-91.

(55) Setchell KDR. 1998. Phytoestrogens: the biochemistry, physiology, and implications for human health of soy isoflavones. Am J Clin Nutr 68: 1333S-1346S.

(56) Setchell KDR, Adlercreutz H. 1988. Mammalian lignans and phyto-oestrogens. Recent studies on their formation, metabolism and biological role in health and disease. In Role of the Gut Flora in Toxicity and Cancer, Rowland IR (ed), Academic Press, London, p. 315-345.

(57) Setchell KDR, Borriello SP, Hulme P, Kirk DN, Axelson M. 1984. Nonsteroidal estrogens of dietary origin: possible roles in hormone-dependent disease. Am J Clin Nutr 40: 569-578.

(58) Setchell KDR, Brown NM, Zimmer-Nechemias L, Brashear WT, Wolfe BE, Kirschner AS, Heubi JE. 2002. Evidence for lack of absorption of soy isoflavone glycosides in humans, supporting the crucial role of intestinal metabolism for bioavailability. Am J Clin Nutr 76: 447-453.

(59) Setchell KDR, Cassidy A. 1999. Dietary isoflavones: biological effects and relevance to human health. J Nutr 129: 758S-767S.

(60) Setchell KDR, Zimmer-Nechemias L, Cai J, Heubi JE. 1997. Exposure of infants to phyto-oestrogens from soybased infant formulas. Lancet 350: 23-27.

(61) Sfakianos J, Coward L, Kirk M, Barnes S. 1997. Intestinal uptake and biliary excretion of the isoflavone genistein in rats. J Nutr 127: 1260-1268.

(62) Shutt DA, Cox RI. 1972. Steroid and phyto-oestrogen binding to sheep uterine receptors in vitro. J Endocrinol 52: 299-310.

(63) Sichel G, Corsaro C, Scalia M, Di Bilio AJ, Bonomo RP. 1991. In vitro scavenger activity of some flavonoids and melanins against $\mathrm{O}_{2}^{-}$. Free Radic Biol Med 11: 1-8.

(64) Sorata Y, Takahama U, Kimura M. 1984. Protective effect of quercetin and rutin on photosensitized lysis of human erythrocytes in the presence of hematoporphyrin. Biochim Biophys Acta 799: 313-317.

(65) Stavric B. 1994. Antimutagens and anticarcinogens in foods. Food Chem Toxicol 32: 79-90.

(66) Tamura M, Hirayama H, Itoh K, Suzuki H, Shinohara K. 2002. Effects of rice starch-isoflavone diet or potato starchisoflavone diet on plasma isoflavone, plasma lipids, cecal enzyme activity, and composition of fecal microflora in adult mice. J Nutr Sci Vitaminol 48: 225-229.

(67) Tamura M, Hirayama H, Itoh K, Suzuki H, Shinohara K. 2002. Effects of soy protein diet on plasma equol and intestinal microflora in adult mice. Bioscience Microflora 21: 121-124.

(68) Tamura M, Hirayama H, Itoh K, Suzuki H, Shinohara K. 2002. Effects of soy protein-isoflavone diet on plasma isoflavone and intestinal microflora in adult mice. Nutr Res 22: 705-713.

(69) Tamura M, Suzuki H, Shinohara K. 2000. Effects of intestinal microflora on the bioavailability of dietary quercetin in adult mice. Food Sci Technol Res 6: 291-293.

(70) Tew B-Y, Xu X, Wang H-J, Murphy PA, Hendrich S. 1996. A diet high in wheat fiber decreases the bioavailability of soybean isoflavones in a single meal fed to women. J Nutr 126: $871-877$.

(71) Ueno I, Nakano N, Hirono I. 1983. Metabolic fate of $\left[{ }^{14} \mathrm{C}\right]$ quercetin in the ACI rat. Jpn J Exp Med 53: 41-50.

(72) Vedavanam K, Srijayanta S, O'Reilly J, Raman A, Wiseman H. 1999. Antioxidant action and potential antidiabetic properties of an isoflavonoid-containing soyabean phytochemical extract (SPE). Phytother Res 13: 601-608.

(73) Verma AK, Johnson JA, Gould MN, Tanner MA. 1988. Inhibition of 7,12-dimethylbenz(a)anthracene- and $\mathrm{N}$ nitrosomethylurea-induced rat mammary cancer by dietary flavonol quercetin. Cancer Res 48: 5754-5758.

(74) Watanabe S, Yamaguchi M, Sobue T, Takahashi T, Miura T, Arai Y, Mazur W, Wähälä K, Adlercreutz H. 1998. Pharmacokinetics of soybean isoflavones in plasma, urine and feces of men after ingestion of $60 \mathrm{~g}$ baked soybean powder (Kinako). J Nutr 128: 1710-1715.

(75) Xu X, Harris KS, Wang HJ, Murphy PA, Hendrich S. 1995. Bioavailability of soybean isoflavones depends upon gut microflora in women. J Nutr 125: 2307-2315. 